\title{
Klinik Araştırma
}

\section{Parsiyel Protez ile Tedavi Edilen Kalça Kırıklı Hastalarda Ameliyat Öncesi Aneminin Hastanede Kalış Süresi Üzerine Etkisi}

The Effect of Preoperative Anemia in Treatment of Hip Fractures with Partial Hip Arthroplasty On Hospital Length of Stay

\author{
Serkan AKÇAY ${ }^{1}$, Akif ALBAYRAK ${ }^{2}$, Hakan BAHAR ${ }^{2}$ \\ Salih SÖYLEMEZ ${ }^{3}$, Murat DEMIROĞLU ${ }^{4}$, Necati EMIRHAN ${ }^{2}$, Bülent KILIÇ ${ }^{5}$
}

1. Sağlık Bilimleri Üniversitesi, Baltalimanı Kemik Hastalıkları Hastanesi, Reyap Hastanesi, Ortopedi ve Travmatoloji Kliniği

2. Să̆lık Bilimleri Üniversitesi, Baltalimanı Kemik Hastalıklarl Hastanesi, Ortopedi ve Travmatoloji Kliniği

3. Bingöl Devlet Hastanesi, Ortopedi ve Travmatoloji Kliniği

4. Medeniyet Üniversitesi, Göztepe Ĕgitim ve Araştırma Hastanesi, Ortopedi ve Travmatoloji Kliniği

5. Gelişim Üniversitesi, Sağlık Bilimleri Fakültesi

$\ddot{O Z E T}$

Preoperatif ve postoperatif düşük hemoglobin değerlerinin kalça cerrahisi sonrası morbidite, mortalite, erken fonksiyonel sonuçlara ve yürüme mesafesine olan etkisine dair farklı sonuçlar bildirilmiştir. Biz bu çalışmada ameliyat öncesi aneminin kalça kırıkl hastalarda cerrahi sonrası mortalite ve hastanede kalış süresi üzerinde etkisi olup olmadığını inceledik. Çalışmaya kliniğimizde parsiyel protez yapularak tedavi edilen 135 kalça dahil edildi. Hasta dosyalart retrospektif olarak incelendi ve hastalara ameliyat öncesi anemisi olanlar ve olmayanlar olarak iki gruba ayrlld. Her iki hasta grubu ortalama yaş, morbidite dağllımı, preoperatif ve postoperatif hemoglobin değerleri, cerrahi öncesi ve sonrası hastane yatış süreleri ve transfüzyon gerekliliği açısından istatistiksel olarak değerlendirildi. Yaptı̆̆ımız çalışmada anemisi olan hastalarda preoperatif dönemde yatış süresinin anemisi olmayan gruba göre anlamlı derecede fazla olduğunu, ancak iki grup arasında postoperatif yatış süresi arasında anlamlı fark olmadığını saptadık.

Anahtar Kelimeler: kalça kırığı; parsiyel protez; anemi; mortalite

\section{SUMMARY}

Objective: The objective of this study was analysing the correlation between preoperative anemia and duration of hospitay stay at preoperative and postoperative stage among patients that had been treated with partial endoprosthesis for treatment of pertrochantericfemoral fractures.

Methods: Medical records of 152 individuals were reviewed retrospectively and 135 patients were included to the study. Preoperative anemia was detected in 87 of patients. Remaining 48 patients hemoglobin levels were within normal ranges. Both patient groups were statistically examined with respect to mean age, distribution of morbidity, preoperative and postoperative hemoglobin values, duration of hospital stay before and after surgery and transfusion requirement.

Results: When hypertension, coronary artery disease, diabetes mellitus, Alzheimer's disease and transfusion ratios are examined, no statistically significant difference was found between groups ( $p>0,05)$. No statistically significant difference was found between the age averages of anemic and non-anemic patients $(p>0,05)$. Preoperative and postoperative hemoglobin values of patients in the anemic group were found to be significantly low compared to the averages of patients in the non-anemic group $(p<0,05)$. Preoperative and postoperative hemoglobin value differences of patients in the non-anemic group were found to be significantly high compared to the differences of patients in the non-anemic group $(p<0,05)$. Preop hospital stay periods of patients with anemia were found to be significantly higher in comparison to those of patients without anemia $(p<0,05)$.

Conclution: Our results showed that there is no statistically significant difference between anemic and nonanemic groups by the means of postoperative hospital stay consistent with the current literature. However we have detected statistically significant longer preoperative hospital stay in anemic group. We believe that this finding is valuable since the fact that duration of preoperative hospital stay increases postoperative mortality.

Keywords: hip fructure; patial prothesis;anemia; mortality
Iletişim Bilgileri
Sorumlu Yazar: Murat DEMIROĞLU

Adres: Medeniyet Üniversitesi Göztepe Eğitim ve Araştırma Hastanesi, Ortopedi ve Travmatoloji Kliniği, İstanbul

Tel: +90 (533) 4847081

E-Posta: drmuratdemiroglu@gmail.com

Makale Geliş: 30.11.2016

Makale Kabul: 08.01.2017 


\section{GİRIŞ}

Kalça kırığı günümüzde giderek artan hızda özelikle yaşlı populasyonda mortalitenin ve morbiditenin ana nedeni olmaya devam etmektedir $(1,2)$. Yaşlılarda yüksek oranda görülen anemi kalça kırığının yol açtığı mortalite ve morbiditeyi arttırmaktadır (3-5). Preoperatif ve postoperatif düşük hemoglobin değerlerinin kalça cerrahisi sonrası morbidite, mortalite, erken fonksiyonel sonuçlara ve yürüme mesafesine olan etkisine dair farklı sonuçlar bildirilmiștir. Hastaneye bașvuru sırasında ölçülen düşük hemoglobin düzeyinin, artmış hastanede kalış süresi ile ve buna paralel olarak yüksek hemoglobin düzeyinin kısa hastane kalış süresi ile ilişkili olduğu bildirilmiştir $(6,7)$. Literatürde anemi ile hastanede kalış süresi ile herhangi bir ilişki saptamayan yayınlar olduğu gibi (8) sadece postoperatif aneminin uzamış hastane kalış süresi ile ilişkili olduğunu belirten yayınlar da mevcuttur (9-11). Bizim bu çalışmadaki amacımız hastaneye başvuru sırasında ve kalça cerrahisi sonrası anemi varlığının hastanede kalış süresi ile olan ilişkisini incelemektir.

\section{MATERYAL ve METOD}

2006-2012 yılları arasında kliniğimizin acil servisine kalça kırığı tanısıyla başvuran 152 hastanın kayıtları incelendi. Retrospektif olarak dizayn edilen çalışmada ICD 10 tanı kodlama sistemine göre femur boyun kırığ (ICD-10 820.0,820.1) ve femur intertrokanterik (ICD-10 820.2,820.3) kodlamaları yapılan hastalar incelendi. Çalışmaya dahil olma kriterleri 65 yaş üstü olmak, parsiyel kalça protezi ile tedavi edilmiş olmak olarak belirlendi. Çalışmadan çıkarılma kriterleri patolojik kırık tanısı almış olmak ve hastane yatış süresi içinde eksitus olması olarak belirlendi.
Buna göre 135 hasta çalışmaya dahil edildi. Olguların 107'si kadın ve 28'i erkekti.

Olgular hastaneye başvuru sırasında yapılan kan tetkiklerinde anemisi olup olmamalarına göre ikiye ayrıldı. Anemi tanısı hemoglobin değerlerinin erkek olgularda $<13.0 \mathrm{~g} / \mathrm{dl}$ ve kadın olgularda $<12$ g/dl olarak kabul edildi. Olguların hastane kayıtlarında bulunan dosyaları incelendi. Olguların yaş cinsiyet, ek morbiditeye neden olan hastalıkları, kan tranfüzyon ihtiyacı, hastanede yatış süresi ve kırık tipi incelendi (Tablo 1). Anemisi olan hasta grubunda 87 ve anemisi olmayan hasta grubunda 48 olgu mevcuttu. Her iki hasta grubu ortalama yaş, morbidite dağılımı, preoperatif ve postoperatif hemoglobin değerleri, cerrahi öncesi ve sonras1 hastane yatış süreleri ve transfüzyon gerekliliği açısından istatistiksel olarak değerlendirildi. Preoperatif hemoglobin değeri hastaneye başvuru sırasında alınan tetkiklerindeki sonuç, postoperatif ise 1 . gün ve eğer yapıldı ise transfüzyon sonrası 24 saat sonra alınan kan tetkiklerindeki hemoglobin değerleri kullanıldı.

Hastaların hepsinde standart olarak preoperatif dönemde mevcut komorbidetelerine göre kardiyoloji, dahiliye, göğüs hastalıkları, nefroloji, endokrinoloji veya varsa başka bir hastalığ1 ilgili klinik ile konsulte edildikten sonra anestezi kliniği tarafindan premedike edildi. Hastaların ek hastalıkları opere olabilecek seviyede stabil hale getirilene kadar ilgili klinikler kontrolünde takip edildi. Hastalar anestezi kliniği tarafından opere edilebileceği onaylandiktan sonra bekletilmeden opere edildi. Preoperatif dönemde kan transfüzyon endikasyonu hemoglobin değerlerinin $<10.0 \mathrm{~g} / \mathrm{dl}$ olması iken postoperatif dönemde kan transfüzyon endikasyonu hemoglobin değerlerinin $<9.0 \mathrm{~g} / \mathrm{dl}$ olması idi.

Tablo 1: Gruplara göre yaş, HT, KAH, DM, alzheimer, transfüzyon ve kırık çeşidi oranları dağılımı.

\begin{tabular}{|c|c|c|c|c|c|c|c|c|}
\hline & & \multicolumn{2}{|c|}{ Anemik grup } & \multicolumn{2}{|c|}{ Anemik olmayan grup } & \multicolumn{2}{|c|}{ Total } & \multirow{2}{*}{$p$} \\
\hline & & $\mathrm{n} ; 87$ & $\% 64,4$ & $\mathrm{n} ; 48$ & $\% 35,6$ & $\mathrm{n} ; 135$ & $\% 100$ & \\
\hline \multicolumn{2}{|c|}{ Ortalama Yaş } & \multicolumn{2}{|c|}{$79,8 \pm 7,58$} & \multicolumn{2}{|c|}{$78,58 \pm 7,52$} & & & 0,371 \\
\hline \multirow{2}{*}{\multicolumn{2}{|c|}{ Hipertansiyon }} & 51 & 59 & 24 & 50 & 75 & 56 & \multirow{2}{*}{0,335} \\
\hline & & 36 & 41 & 24 & 50 & 60 & 44 & \\
\hline \multirow{2}{*}{\multicolumn{2}{|c|}{$\mathrm{KAH}$}} & 21 & 24 & 14 & 29 & 35 & 26 & \multirow{2}{*}{0,523} \\
\hline & & 66 & 76 & 34 & 71 & 100 & 74 & \\
\hline \multirow{2}{*}{\multicolumn{2}{|c|}{ DM }} & 8 & 9,2 & 6 & 13 & 14 & 10 & \multirow{2}{*}{0,565} \\
\hline & & 79 & 91 & 42 & 88 & 121 & 90 & \\
\hline \multirow{2}{*}{\multicolumn{2}{|c|}{ ALZEIMER }} & 8 & 9,2 & 2 & 4,2 & 10 & 7,4 & \multirow{2}{*}{0,494} \\
\hline & & 79 & 91 & 46 & 96 & 125 & 93 & \\
\hline \multirow{2}{*}{ Transfüzyon } & Var & 64 & 74 & 37 & 77 & 101 & 75 & \multirow{2}{*}{0,652} \\
\hline & Yok & 23 & 26 & 11 & 23 & 34 & 25 & \\
\hline \multirow{2}{*}{ Kırık Çeşidi } & İntertrokanterik & 11 & 13 & 5 & 10 & 16 & 12 & \multirow{2}{*}{0,623} \\
\hline & Boyun & 76 & 87 & 43 & 90 & 119 & 88 & \\
\hline
\end{tabular}




Tablo 2: Gruplara göre Hb ve preop-postop Hb farkları ortalama dağılımı.
\begin{tabular}{|l|c|c|c|}
\hline & Anemik grup & Anemik olmayan grup & \multirow{2}{*}{$\boldsymbol{p}^{*}$} \\
\cline { 2 - 4 } & Ort. \pm SS & Ort. $\pm S S$ & \\
\hline Preop Hb & $10,47 \pm 1,23$ & $13,15 \pm 0,91$ & $\mathbf{0 , 0 0 1}$ \\
\hline Postop Hb & $9,91 \pm 0,89$ & $10,55 \pm 1,24$ & $\mathbf{0 , 0 0 3}$ \\
\hline Fark & $-0,57 \pm 1,38$ & $-2,6 \pm 1,06$ & $\mathbf{0 , 0 0 1}$ \\
\hline
\end{tabular}

* independent sample t test, $\mathrm{Hb}$ : Hemogobin.

Tablo 3: Olguların gruplara göre preoperatif ve postoperatif yatış süreleri ortalama dağılımı.

\begin{tabular}{|c|c|c|c|c|c|c|}
\hline & & $\mathrm{n}$ & Ort. \pm SS & Min & Max & $p^{*}$ \\
\hline \multirow{3}{*}{$\begin{array}{c}\text { Preop } \\
\text { yatış } \\
\text { süresi }\end{array}$} & Anemik olanlar & 87 & $5,18 \pm 3,28$ & 1 & 17 & \multirow{2}{*}{0,008} \\
\hline & Anemik olmayanlar & 48 & $3,8 \pm 2,58$ & 1 & 14 & \\
\hline & Total & 135 & $4,66 \pm 3,1$ & 1 & 17 & \\
\hline \multirow{3}{*}{$\begin{array}{c}\text { Postop } \\
\text { yatış } \\
\text { süresi }\end{array}$} & Anemik olanlar & 87 & $6,35 \pm 4,54$ & 2 & 31 & \multirow{2}{*}{0,171} \\
\hline & Anemik olmayanlar & 48 & $5,33 \pm 3,01$ & 2 & 20 & \\
\hline & Total & 135 & $5,97 \pm 4,06$ & 2 & 31 & \\
\hline
\end{tabular}

*Mann Whitney $U$ analizi.

Postoperatif dönemde stabil olan ve ek hastalığ 1 olmayan hastalar en az 2 gün takip edildi. Ek hastalığı bulunan veya başka bir nedenle takip gerektiren hastalar vital bulgularının stabil olduğu gözlenip ek hastalıkları ve yapılan cerrahi için stabil hale geldikten sonra taburcu edildi.

\section{ISTATIKSEL ANALIZ}

Verilerin istatistiksel analizi SPSS 15.0 Windows paket programında $\% 95$ güvenle yapıld1. Preop ve postop hastanede yatış süreleri Kolmogrov-Smirnov analizi ile değerlendirildiğinde verilerin normal dağılıma uygun olmadığ saptand1. Bu nedenle, iki grup arasındaki karşılaştırmada Preoperatif ve postoperatif yatış süreleri ortalama dağılımı için Mann Whitney U analizi, grup içi preoperatif-postoperatif değerler arasındaki karşılaştırmada Wilcoxon Signed Ranks istatistiksel analizleri kullanıldı. Gruplara göre yaş, $\mathrm{Hb}$ ve preoperatif- postoperatif $\mathrm{Hb}$ farkları ortalama dağılımı için independent sample t test, anemisi olan ve olmayan grupların preoperatif - postoperatifHb ortalama dağılımı için Paired sample t test ve anemisi olan ve olmayan gruplar aras1 preperatif-postoperatif $\mathrm{Hb}$ farklarına göre yatış süreleri ortalama dağılımı için independent sample $t$ test ve Mann Whitney U testi kullanıldı. $\mathrm{P}<0,05$ istatistiksel olarak anlamlı kabul edildi.

\section{SONUÇLAR}

Hastaneye başvuru anındaki hemoglobin değerine göre, olgular anemisi olan ve olmayan olmak üzere iki ana gruba ayrıldı. Anemisi olmayan grupta 38'i kadin ve 10'u erkek olmak üzere 48 olgu mevcuttu.
\} Tablo 4: Anemisi olan ve anemik olmayan olguların preoperatif ve postoperatif yatş süreleri ortalama dağılımı.

\begin{tabular}{|c|c|c|c|c|c|c|c|}
\hline & \multicolumn{3}{|c|}{ Grup } & Ort. $\pm S S$ & Min. & Max. & $p^{*}$ \\
\hline \multirow{2}{*}{$\begin{array}{l}\text { Anemisi } \\
\text { olanlar }\end{array}$} & \multicolumn{3}{|c|}{ Preop yatış süresi } & $5,18 \pm 3,28$ & 1 & 17 & \multirow{2}{*}{0,125} \\
\hline & \multicolumn{3}{|c|}{ Postop yatş süresi } & $6,35 \pm 4,54$ & 2 & 31 & \\
\hline \multirow{2}{*}{$\begin{array}{l}\text { Anemisi } \\
\text { olmayanlar }\end{array}$} & \multicolumn{3}{|c|}{ Preop yatış süresi } & $3,80 \pm 2,58$ & 1 & 14 & \multirow{2}{*}{0,001} \\
\hline & \multicolumn{3}{|c|}{ Postop yatı̧ süresi } & $5,33 \pm 3,01$ & 2 & 20 & \\
\hline \multicolumn{8}{|c|}{ * Wilcoxon signed ranks analizi. } \\
\hline \multicolumn{8}{|c|}{$\begin{array}{l}\text { Tablo 5: Anemisi olan ve anemisi olmayan olgularda preoperatif-postop } \\
\text { eratif } \mathrm{Hb} \text { farklarına göre yatş süreleri ortalama dağılımı. }\end{array}$} \\
\hline \multirow{2}{*}{ Fark } & & & \multicolumn{3}{|c|}{ Yatış süresi } & & \multirow{2}{*}{$p$} \\
\hline & & $\mathrm{n}$ & Ort. & SS & Ort. $\pm S$ & & \\
\hline \multicolumn{8}{|c|}{ Anemisi olan hastalarda pre-postoperatif Hb değerleri değişimi } \\
\hline \multicolumn{2}{|l|}{ Eksi yönde } & 58 & 6,34 & 4,23 & $6,34 \pm 4$ & & \multirow{2}{*}{$0,280 *$} \\
\hline \multicolumn{2}{|l|}{ Artt Yönde } & 29 & 5,62 & 1,97 & \multicolumn{2}{|c|}{$5,62 \pm 1,97$} & \\
\hline \multicolumn{8}{|c|}{ Anemisi olmayan hastalarda pre-postoperatif Hb değerleri değişimi } \\
\hline \multicolumn{2}{|c|}{$2 \mathrm{~g} / \mathrm{dl}$ 'den az düşüş } & 14 & 6,09 & 5,11 & $6,09 \pm 5$ & & \multirow{2}{*}{$0,266^{* *}$} \\
\hline \multicolumn{2}{|c|}{$2 \mathrm{~g} / \mathrm{dl}$ ve üzeri düşüş } & 34 & 5,82 & 2,44 & $5,82 \pm 2$ & & \\
\hline
\end{tabular}

* Independent sample t test, **Mann Whitney U, Hb: Hemoglobin.

Anemisi olan grupta ise 69'u kadın ve 18 'i erkek olmak üzere 87 olgu mevcuttu. Her iki grup arasında kan transfüzyon ihtiyacı ile hipertansiyon (HT), koroner arter hastal1ğ 1 (KAH), diabetes mellitus (DM) Alzheimer ve kırık çeşidi gibi ek mordiditelerin dağıl1mı Tablo1'de ayrıntılı olarak görülmektedir. Grupların homojen dağılımı olduğu tespit edildi.

Grupların yaş dağılımı, HT, KAH, DM, Alzeimer, kırık çeşidi ve transfüzyon oranları dağılımı incelendiğinde gruplar arasında istatistiksel olarak anlamlı fark bulunmadı $(p>0,05)$. Anemik grupta transfüzyon yapılan 64 hastanın 29 tanesi preop transfüze edildi.

Gruplarin preoperatif ve postoperatif hemoglobin değerleri dağılımı Tablo 2'de incelendi. Anemisi olan grup olgularının preoperatif ve postoperatif hemoglobin değerleri ortalamalar1 anemisi olmayan grup olgular1nın ortalamalarından istatistiksel olarak anlamlı düşük bulundu $(\mathrm{p}<0,05)$.

Anemisi olmayan grup olgularının preoperatif ve postoperatif hemoglobin değerleri fark1 ortalamalar1 anemisi olan grup olgular1nın fark ortalamalarından istatistiksel olarak anlamlı yüksek bulundu $(\mathrm{p}<0,05)$. Olguların gruplara göre preop ve postop yatış süreleri ortalama dağglımı Tablo 3 'te incelendi.

Anemisi olan hastaların preop yatış süreleri anemisi olmayan hastaların yatış sürelerinden istatistiksel olarak anlamlı yüksek bulundu $(p<0,05)$. Anemik olan ve olmayan hastaların postop yatıș süreleri arasında istatistiksel olarak anlamlı fark bulunmadi $(\mathrm{p}>0,05)$. 
Anemisi olan ve anemisi olmayan olguların preopertif ve postoperatif yatış süreleri Tablo 4'te görülmektedir. Anemisi olan olguların preop yatış süreleri ile postop yatış süreleri arasinda istatistiksel olarak anlamlı fark bulunmazken $(p>0,05)$; anemisi olmayan olguların postop yatış süreleri, preop yatış sürelerinden istatistiksel olarak anlamlı yüksek bulundu $(\mathrm{p}<0,05)$.

Anemisi olan ve anemisi olmayan olguların preoperatif-postoperatif hemoglobin değerleri farklarının hastane yatış süreleri ortalama dağılımı ile olan ilişkisi Tablo 5'te incelendi. Anemisi olan ve anemisi olmayan olgularda preoperatif-postoperatif hemoglobin değerleri arasındaki farklarına göre yatış süreleri ortalama dağılımı incelendiğinde gruplar arasında istatistiksel olarak anlamlı fark bulunmadı $(\mathrm{p}>0,05)$. Anemik grupta preop transfüze edilen 29 hastanın 28 'inde ve transfüze edilmeyen 1 hastada postop hemogramda artış saptand. Anemik olmayan grupta postop tüm hemogramlarda düşüş saptandi.

\section{TARTIŞMA}

Ortalama yaşam sürelerinin tüm dünyada artmasiyla beraber en fazla cerrahisi yapilan kalça kırıkları çok ciddi bir ekonomik yük oluşturmaktadır. Bu nedenle bu hasta gruplarında kırıkların oluşmasını önlemek, tedavisini basit, ucuz ve kolay ulaşılabilir hale getirmek için çok yaygın çalışmalar yapılmıştır. Ancak bu hasta grubunun genellikle çok fazla ek hastalığ 1 olması bizim serimizde de görüldüğü gibi preoperatif ve postoperatif dönemde çok uzun yatış süreleri gerektirebilmektedir. Yatış sürelerini kısaltabilmek için hastaların birçok laboratuvar değeri incelenmiş ve tartışmalı birçok sonuca varılmıştır (7-9). Literatürde kalça kırığı sonras1 hastanede yatıș süresine ile hem preoperatif hem de postoperatif hemoglobin değerlerinin ilişskisini inceleyen yayınlarda mevcuttur. Bu bildirilerde de perioperatif hemoglobin değerlerinin hastanede kalış süresine olan etkisine dair tam bir görüş birliğine varılmadığ görülmektedir (10-11).

Literatürde kalça kırığı tanısıyla başvuran hastaların \%30-45 arasında anemisi olduğu bildirilmiştir (12). Bu yüksek oran, perioperatif aneminin özellikle geriatrik hasta popülasyonunun oluşturduğu kalça kırıkları için cerrahi sonras1 mortaliteye, morbiditeye, erken fonksiyonel sonuçlara ve hastanede yatış sürelerine olan etkilerinin incelenmesine neden olmuştur. Gruson ve ark. Yaptıkları çalışmada başvuru sırasında anemik olan hasta grubunun olmayan gruba göre hastanede kalış süresinin uzun olduğunu ve aneminin hastanede kalış süresini arttıran öngörülebilen bir faktör olarak tanımlamışlardır (10). Dunne ve arkadaşları cerrahi uygulanan hastalarda perioperatif aneminin etkisini inceledikleri çalışmada da preoperatif düşük hematokrit değerlerinin hastanede yatış süresini arttırdığını tespit etmişlerdir (13). Halm EA ve arkadaşlarının çalışmalarında da yüksek hemoglobin değerlerinin kısa hastanede kalış süresi ile ilişkili bulmuşlardır (6). Bizim çalışmamızda ise başvuru sırasında anemi tespit edilen grubun preop yatış süresi anemisi olmayan gruba göre istatistiksel olarak anlamlı düzeyde yüksek bulundu.

Postoperatif aneminin hastane kalış süresine olan etkisi incelendiğinde Foss NB ve arkadaşları ile Halm EA çalışmalarında posoperatif anemi ile hastane yatış süresinin uzaması arasında belirgin bir ilişkiden söz etmişlerdir $(6,9)$. Willems JM ve arkadaşlarının çalışmalarında benzer olarak postoperatif hemoglobin değerleri ile hastanede kalış süresi ile ters oranlı bir ilişkiden söz etmişlerdir (11). Bizim çalışmamızda ise yukarıda belirttiğimiz iki çalişmanın aksine postoperatif anemisi olan grup ile anemisi olmayan grup arasinda postoperatif hastanede kalış süresi arasında anlamlı bir farklılik saptanmadi. Bununla birlikte Vochteloo $\mathrm{JH}$ ve arkadaşlarının preop anemisi olan ve olmayan kalça kırığg cerrahisi geçiren 1262 olguyu inceledikleri çalışmalarında, anemisi olan olguların, anemik olmayan gruba göre daha kısa hastane yatış süresi olduğunu bildirmişlerdir (14). Parker MJ'nin çalışmasında preoperatif anemisi olan olgularda, postoperatif kan transfüzyonu yapılan ile yapılmayan grup arasında hastanede yatış süresi açısından anlamlı bir fark bildirilmemiştir (15).

Nitekim bizim çalıșmamızda da her iki grup için postoperatif transfüzyon gerektirmediği sürece hemogramdaki $2 \mathrm{~g} / \mathrm{dl}$ 'nin üzerindeki düşüşlerin bile postoperatif yatışı uzatmadığ 1 görülmektedir. Gene aynı tabloda (Tablo 5) görüldüğü üzere anemisi olan grupta 29 hastada preoperatif dönemde transfüzyon yapılmış ve postop yatış süreleri preop transfüzyon yapılmayan 58 diğer anemik hastayla karşılaştırıldığında anlamlı fark saptanmamıştır.

Hagino başvuru anında anemisi olan ve olmayan hastaları değerlendirdiği çalışmasında hastane yatış süresi açısından degerlendirildiğinde her iki grup arasında istatistiksel anlamlı farklılık saptamadıklarını bildirmiştir (15). Lawrence ve arkadaşları postoperatif hemoglobin değerleri ile hastanede yatış süresini karşılaştırdıkları çalışmalarında 
hemoglobin düzeyi gruplandırılmış olguların hastanede yatış süresi arasında istatistiksel farklılık saptamadıklarını bildirmişlerdir (16). Yaptığımız çalışmada preop anemisi olan olguların postoperatif hemoglobin değerlerini artan ve azalan olarak iki gruba ayırıp incelediğimizde postop hastanede kalış süresi açısından Lawrence ve arkadaşlarının sonuçlarıyla uyumluydu.

Çalışmamızdaki preop anemisi olan ve olmayan hasta grubunun postoperatif hastanede yatış süresi incelendiğinde Hagino ve arkadaşlarının sonuçlarıyla uyumlu olarak anlamlı istatistiksel farklılık saptanmadi.

\section{ÇIKARIMLAR}

Yaptığımız çalışma preoperatif anemisi olan ve olmayan olmak üzere iki ana grup içermekle birlikte grupların hem preop ve postop hemoglobin değerleri ile hastanede yatış sürelerini preoperatif ve postoperatif olarak incelemesi literatürdeki sonuçlara göre farklılık olușturmuştur. Çalıșmamızın zayıf yönü gruplardaki olgu sayısının azlığı ve retrospektif olmasidir.

Sonuçları açısından anemik olguların preop yatış süresinin anemik olmayanlara göre uzun olması literatürde pek değinilmemiş olması nedeniyle değerlidir. Özelikle cerrahi öncesi preoperatif hastane yatış süresinin postoperatif mortaliteyi arttırdığına dair yayınlar göz önüne alındığında bu sonucu önemsemekteyiz. Postop yatış süresi açısından değerlendirildiginde anemisi olan ve olmayan gruplar arasında istatistiksel fark saptanmaması literatürle uyumlu bulunmuştur.

Ayrıca çalışmamız anemiyi endikasyon $(\mathrm{Hgb}<10 \mathrm{~g} / \mathrm{dl}) \quad$ olmadiğ 1 sürece preoperatif dönemde transfüzyon yaparak tedavi etmeye çalışmanın postoperatif yatış süresini kısaltmadığını ortaya koymuştur.

\section{KAYNAKLAR}

1. Johnell $O$. The socioeconomic burden of fractures: today and in the 21st century. Am J Med 1997;103 (August (2A)):20S-5S

2. Kannus P, Parkkari J, Sievanen H, Heinonen A, Vuori I, Jarvinen M. Epidemiology of hip fractures. Bone 1996; 18 (Janu$\operatorname{ary}(1$ Suppl.)):57S-63S.

3.Izaks GJ, Westendorp RG, Knook DL. The definition of anemia in older persons. JAMA. 1999;281:1714-1717.
4. Salive ME, Cornoni-Huntley J, Guralnik JM, et al. Anemia and hemoglobin levels in older persons: relationship with age, gender, and health status. J Am Geriatr Soc. 1992;40:489-496.

5. Ania BJ, Suman VJ, Fairbanks VF, et al. Incidence of anemia in older people: an epidemiologic study in a well-defined population. J Am Ger Soc. 1997;45:825-831.

6. Halm EA, Wang JJ, Boockvar K, Penrod J, Silberzweig SB, Magaziner J, Koval KJ, Siu AL. The effect of perioperative anemia on clinical and functional outcomes in patients with hip fracture. J Orthop Trauma. 2004 Jul;18 (6):369-74.

7. Vochteloo AJ, Borger van der Burg BL, Mertens B, Niggebrugge AH, de Vries MR, Tuinebreijer WE, Bloem RM, Nelissen $R G$, Pilot P. Outcome in hip fracture patients related to anemia at admission and allogeneic blood transfusion: an analysis of 1262 surgically treated patients. BMC Musculoskelet Disord. 2011 Nov 21;12:262. doi: 10.1186/1471-2474-12-262.

8. Tetsuo Hagino, Satoshi Ochiai, Eiichi Sato, Shingo Maekawa, Masanori Wako, Hirotaka Haro The relationship between anemia at admission and outcome in patients older than 60 years with hip fracture. J Orthop Traumatol. 2009 September; 10 (3): 119-122. Published online 2009 August 26. doi: 10.1007/ s10195-009-0060-8

9. Foss NB, Kristensen MT, Kehlet H. Anaemia impedes functional mobility after hip fracture surgery. Age Ageing. 2008 Mar;37 (2):173-8. doi: 10.1093/ageing/afm161.

10. Gruson KI, Aharonoff GB, Egol KA, Zuckerman JD, Koval $K J$. The relationship between admission hemoglobin level and outcome after hip fracture. J Orthop Trauma. 2002 Jan;16 (1):39-44.

11. Willems JM, de Craen AJ, Nelissen RG, van Luijt PA, Westendorp RG, Blauw GJ. Haemoglobin predicts length of hospital stay after hip fracture surgery in older patients. Maturitas. 2012 Jul;72 (3):225-8. doi: 10.1016/j.maturitas.2012.03.016. Epub 2012 Apr 21

12. Moppett IK, Wiles MD, Moran CG, Sahota O. The Nottingham Hip Fracture Score as a predictor of early discharge following fractured neck of femur. Age Ageing. 2012 May;41 (3):3226. doi: 10.1093/ageing/afr142. Epub 2011 Nov 13. Erratum in: Age Ageing. 2013 Mar;42 (2):270.

13. Dunne JR, Malone D, Tracy JK, Gannon C, Napolitano LM. Perioperative anemia: an independent risk factor for infection, mortality, and resource utilization in surgery. J Surg Res. 2002Feb;102 (2):237-44.

14. Vochteloo AJ, Borger van der Burg BL, Mertens B, Niggebrugge AH, de Vries MR, Tuinebreijer WE, Bloem RM, Nelissen $R G$, Pilot $P$. Outcome in hip fracture patients related to anemia at admission and allogeneic blood transfusion: an analysis of 1262 surgically treated patients. BMC Musculoskelet Disord. 2011 Nov 21;12:262. doi: 10.1186/1471-2474-12-262.

15. Parker MJ. Randomised trial of blood transfusion versus a restrictive transfusion policy after hip fracture surgery. Injury. 2013 Dec;44 (12):1916-8. doi: 10.1016/j.injury.2013.04.033. Epub 2013 Jun 4.

16. Lawrence VA, Silverstein JH, Cornell JE, Pederson T, Noveck H, Carson JL. Higher Hb level is associated with better early functional recovery after hip fracture repair. Transfusion. 2003 Dec;43 (12):1717-22. 